\section{International Scientific Journal Theoretical \& Applied Science}

Nikolay Vasilevich Penshin candidat of economic sciences, Head of the Department "Organization of transportation and road safety" Tambov state technical University, Russia avtobd@mail.ru

Victor Yurievich Ivlev

Undergraduate, Mechanical engineer Aor Nekrasovskoe RTP, city of Rasskazovo, Russia victor.pshenihniy_7@mail.ru

SECTION 27. Transport.

\title{
TECHNOLOGICAL ROAD SAFETY IN RUSSIA
}

Abstract: Ensuring road safety is the activity aimed at the prevention of causes of traffic accidents, reduce the severity of their consequences. Road transport accident rate causes enormous damage to the Russian economy.

Key words: Car, active and passive safety, development of transport infrastructure.

Language: Russian

Citation: Penshin NV, Ivlev VY (2015) TECHNOLOGICAL ROAD SAFETY IN RUSSIA. ISJ Theoretical \& Applied Science 12 (32): 99-102.

Soi: http://s-o-i.org/1.1/TAS-12-32-19 Doi: crossef http://dx.doi.org/10.15863/TAS.2015.12.32.19

\section{УДК 502.7}

\section{ТЕХНОЛОГИЧЕСКАЯ БЕЗОПАСНОСТЬ АВТОМОБИЛЬНОГО ТРАНСПОРТА В РОССИИ}

Аннотация: Обеспечение безопасности дорожного движения - это деятельность, направленная на предупреждение причин возникновения дорожно-транспортных происшествий, снижение тяжести их последствий. Дорожно-транспортная аварийность наносит огромный ущерб экономике России.

Ключевые слова: Автомобиль, активная и пассивная безопасность, развитие транспортной инфраструктуры.

За первое полугодие 2015 г. в России произошло 79199 ДТП (-6,3\% к уровню январяиюня 2014 г.). В них погибло 9712 человек ($11,9 \%)$, ранено 99740 человек $(-6,8 \%)$, сообщает ГИБДД России. Пик числа аварий пришелся на выходные, субботу и воскресенье, с 17 до 18 часов. Из-за плохих дорог произошло 30667 ДТП, а по вине пьяных водителей - 5396.

ГИБДД обнародовала статистику аварий за первое полугодие этого года. Практически по всем параметрам идет снижение аварийности. Всего за этот период произошло 79199 происшествий (-6,3\% к АППГ), из-за нарушений ПДД водителями транспортных средств случилось 68412 ДТП $(-6,7 \%)$, в которых погибло 8208 (-12,9\%) человек, ранено 89936 ($7,2)$ человек.

Чаще всего аварии происходят в выходные дни: по субботам - 12235 (-9,5\%) аварий, в воскресные дни - 12464 случая (+2\%). Самым аварийным по итогам полугодия стало время с 17 до 18 часов - на этот период за шесть месяцев пришлось 5166 ДТП (-2,6\%).

По вине пьяных водителей легковых автомобилей, грузовиков и автобусов с января по конец июня произошло 5396 ДТП, в них было ранено 7914 человек, погибло 1157 человек. Чаще всего аварии провоцируют водители-мужчины, по их вине за 6 месяцев было совершено 66968 ($8,4 \%)$ ДТП против $9062(+3,5 \%)$ по вине водителей-женщин.

Дорожно-транспортных происшествий с участием детей в возрасте до 16 лет за 6 месяцев текущего года произошло $8507(-3,4 \%)$, в них ранено 8990 детей $(-3,2 \%)$ и погибло 305.

Самой частой причиной аварии является столкновение транспортных средств, из-за этого произошло 32754 (-7,2\%) ДТП, на втором месте по частотности стал наезд на пешехода - 23724 ДТП (-1,4\%), в которых ранено 22325 человек ($1,3 \%)$ и погиб 2731 человек $(-1,9 \%)$. Замыкает тройку антилидеров опрокидывание ТС - 7096 случаев $(-27,9 \%)$, в таких происшествиях ранено 8986 человек (-28,7\%), погибли 1161 (-27,2\%).

На пешеходных переходах было совершено 5707 ДТП (+7,6\%), где ранено 5924 (+7,3 \%) и погибло 343 человека $(+1,8)$.

По вине технически неисправных ТС случилось 945 аварий $(+14,4 \%)$, в которых 
погибло 172 человека (-3,9\%), ранено 1364 человека $(+12 \%)$.

Как и прежде, совершению ДТП сопутствовали неудовлетворительные условия содержания и обустройства улично-дорожной сети (НДУ). С января по июнь зарегистрирован 30667 таких случаев $(-4,1 \%)$, в которых ранено 38754 человека $(-4,9 \%)$, погибло - 3873 ($10,2 \%)$.

Напомним, в прошлом году на дорогах России произошло 199720 дорожнотранспортных происшествий, в которых погибло 26963 человека. Из этого числа по вине пьяных водителей - 3420 человек, а из-за плохих дорог расстались с жизнью 7038 человек.

Если рассматривать автомобиль, то сущность основных функций активной безопасности - отсутствие внезапных отказов всех его систем (отказная безопасность), особенно связанных с возможностью маневра автомобиля, а также обеспечение возможности для водителя уверенно, с комфортом управлять механической подсистемой "Автомобиль-Дорога" (эксплуатационная безопасность).

Важной функцией активной безопасности является соответствие тяговой и тормозной динамики автомобиля дорожным условиям и транспортным ситуациям, а также психофизиологическим особенностям водителя.

Следующим важным компонентом активной безопасности системы являются дорожные условия и организация дорожного движения.

Следует также отметить, что трудно разделять влияние дорожных условий и организации дорожного движения на активную и пассивную безопасность, то есть выделить, какие именно параметры повлияли на вероятность возникновения происшествия и какие - усилили тяжесть последствий. Можно рассматривать влияние дорожных условий и организации движения как на активную, так и на пассивную безопасность.

К дорожным условиям, снижающим безопасность, относятся следующие факторы:

- несоответствие размеров геометрических элементов дороги (ширины проезжей части, габаритов мостов, путепроводов, радиусов закруглений дорог в плане, уклонов, виражей) фактическим скоростям движения автомобиля;

- неудачное сочетание элементов плана и профиля дороги на соседних участках, способствующих возрастанию, а потом резкому снижению скорости движения (кривые в плане малых радиусов в конце спусков или горизонтальных прямых; короткие горизонтальные прямые на извилистых трассах);

- плохое состояние проезжей части и обочин (недостаточная ровность и шероховатость покрытия, рыхлый грунт неукрепленных обочин, грязь на проезжей части от снега, дождя, камни и другие посторонние предметы);

- неправильное расположение массивных препятствий (опор освещения, дорожных знаков, опор путепроводов, зданий, автобусных павильонов и т.д.);

- недостаточная информация о границах проезжей части, полосах движения, протяженности и форме опасных участков, характере возможной опасности, рекомендуемых действиях по управлению автомобилем и ограничениях в движении, отсутствии заграждений, удерживающих автомобиль от съездов с дороги и переездов через разделительную полосу);

- плохая видимость ночью; гололед, туман, атмосферные осадки.

Следует помнить, что чем выше технические возможности автомобиля, тем более сильное влияние оказывают дорожные условия на процесс движения.

По оценкам специалистов, плохие дорожные условия повышают стоимость эксплуатации автомобиля в 2,5-4 раза. В частности, срок службы автопокрышек сокращается на 30\%, а удельный расход горючего повышается в 1,5-2 раза.

Рекомендации по повышению активной и пассивной безопасности автомобильных дорог:

- установка дорожных ограждений (влияет как на возникновение происшествий вследствие съезда с дороги или выезда на полосу встречного движения, так и на снижение тяжести последствий ДТП);

- уменьшение протяженности участков дорог, характеризующихся высокой частотой съездов автомобиля (влияет на вероятность наступления ДТП и на снижение тяжести последствий);

- сокращение длины участков с высокими насыпями за счет длины выемок (при проектировании дорог) (влияет на вероятность наступления ДТП и на снижение тяжести последствий);

- снижение высоты насыпи, в частности, путем устройства дренажей (подсыпка грунта) (влияет на снижение тяжести последствий);

- обустройство широкой разделительной полосы на дорогах 1-й технической категории и выполнение раздельного трассирования земляного полотна для разных направлений движения (влияет на вероятность наступления ДТП и на снижение тяжести последствий);

- проектирование пологих откосов выемок на внешней стороне кривых в плане, уменьшение глубины водоотводных канав применением дренажных устройств (влияет на снижение тяжести последствий); 

поперечного профиля насыпи в районах с высокой ценностью земельных угодий (влияет на вероятность наступления ДТП);

- уменьшение частоты размещения массивных сооружений и конструкций в зоне шириной 15 м у края проезжей части (влияет на вероятность наступления ДТП и на снижение тяжести последствий);

- снижение травмоопасности конструкций, используемых для обустройства дорог, применение конструкций ограждений с прогрессивными деформационными характеристиками (влияет на снижение тяжести последствий).

В сфере организации дорожного движения можно выделить следующие факторы, влияющие на активную и пассивную безопасность системы:

- схемы движения транспортных средств;

- схемы движения пешеходных потоков;

- технические средства управления и организации дорожного движения.

Для повышения активной безопасности за счет средств организации движения необходимо:

- выявить места повышенной опасности движения транспортных средств;

- ликвидировать опасные дорожные условия (ремонт и строительство дорог, обустройство разделительной полосы, придорожное обустройство и т.д.);

- сократить количество конфликтных точек путем:

- канализации движения транспортных потоков;

- разделения транспортных и пешеходных потоков;

транспорта;

ограничения скорости движения

- регулирования состава потока транспорта;

- выравнивания скорости движения транспорта;

- запрещения маневров;

- введения кругового движения;

- принудительного регулирования движения и др.

Всеми этими средствами достигается однородность транспортного потока, выравнивание скоростей движения, следовательно, повышается уровень безопасности дорожного движения. Ограничение скоростей движения, причем, не только в сторону уменьшения, но и увеличения также является эффективной мерой, это мероприятие может носить как временный и локальный, так и постоянный характер.

Рациональная организация маршрутов движения транспорта позволяет не только более эффективно использовать транспорт, но и улучшить показатели безопасности движения и экологические характеристики.

Автомобильный транспорт, как было отмечено, является сложной технической системой (СТС).

Появлению нарушений в СТС предшествует определённое (предкризисное, граничное) состояние ответственного технологического процесса перевозки, которое вызывается следующими неблагоприятными причинами: опасными отказами транспортных средств, ошибками человека, дорожными факторами, влиянием окружающей среды. Такое состояние технологического процесса будем называть опасной ситуацией (OC). При этом под опасным отказом понимают такой отказ системы, который приводит к опасной ситуации (ОС). Необходимость введения понятия ОС вызвана тем обстоятельством, что непосредственно выявить неблагоприятную причину при реализации ответственного технологического процесса не всегда возможно, так как проявляется она часто косвенно через ОС. ОС может привести к нарушениям безопасности функционирования системы, а может и не привести, если будут предприняты эффективные меры по недопущению перехода ОС в нарушение безопасности. Это не значит, что не следует предпринимать меры по выявлению опасного отказа, ошибок человека и воздействия среды и ждать, пока они приведут к ОС. Напротив, там, где это возможно, должны быть направлены все усилия на выявление этих неблагоприятных причин и предотвращение появления ОС.

Таким образом, модель безопасности СТС строится с учетом следующих условий. Возникновение ДТП, как меры риска, является следствием нарушения безопасности функционирования, которая определяется ОС. На этом этапе создается возможность управлять безопасностью путем идентификации ОС и недопущения ее перехода в нарушение безопасности функционирования. ОС вызывается неблагоприятными причинами: опасными отказами ТС, ошибками человека, воздействием внешней среды, зависящими, в свою очередь, от различных факторов. При этом следует использовать любой шанс для управления безопасностью на этапах перехода неблагоприятной причины в ОС, а также каждого фактора в неблагоприятную причину. Для этого по каждой СТС на основе квалифицированного анализа статистики нарушений безопасности функционирования систем должны быть определены перечни ОС, неблагоприятных причин, факторов и необходимых воздействий для управления безопасностью в разных точках модели. 


\begin{tabular}{l|lrl|l|ll} 
& ISRA (India) & $=\mathbf{1 . 3 4 4}$ & SIS (USA) & $=\mathbf{0 . 9 1 2}$ & ICV (Poland) & $=\mathbf{6 . 6 3 0}$ \\
Impact Factor: & ISI (Dubai, UAE) $=\mathbf{0 . 8 2 9}$ & PUHIL (Russia) $=\mathbf{0 . 1 7 9}$ & PIF (India) & $=\mathbf{1 . 9 4 0}$ \\
& GIF (Australia) & $\mathbf{0 . 5 6 4}$ & ESJI (KZ) & $=\mathbf{1 . 0 4 2}$ & & \\
& JIF & $=\mathbf{1 . 5 0 0}$ & SJIF (Morocco) $=\mathbf{2 . 0 3 1}$ & &
\end{tabular}

На современном этапе развития заслуживает внимание организация безопасности дорожного движения в Японии. Развитие транспортной инфраструктуры и организация дорожного движения входит в компетенцию государственной гражданской организации.

К основным функциям организации относятся:

- информационное обеспечение водителей на магистралях с использованием электронных табло, информационного радиоканала, управляемых дорожных знаков;

- повышение уровня безопасности дорожного движения за счет своевременного предупреждения о возникших затруднениях на дорогах (вызов служб эвакуации транспорта, взаимодействие $\mathrm{c}$ дорожной полицией при возникновении ДТП, страховыми компаниями и вещательными средствами массовой информации).
Ocобое внимание для обеспечения безопасности на автотранспортных дорогах в Швеции, уделяется проблеме обустройства, совершенствования и развития улично-дорожной сети. Те мероприятия, которые реализуются на национальных и региональных дорогах финансируются государством.

Совершенствование дорог местного значения финансируются из муниципальных бюджетов. Муниципалитеты могут запросить дополнительные средства у Государственного управления дорог для проведения мер по повышению безопасности дорожного движения. Местным органам власти поручено осуществлять работу по обеспечению безопасности дорожного движения посредством совершенствования его регулирования в крупных городах, а также своей деятельности в качестве работодателя и заказчика транспорта.

\section{References:}

1. (1985) SNiP 2.05.02 - 85 "motor roads".

2. Klinkovsky GI (2015) "the traffic Organization".

3. Konoplyanko VI (2015) "Organization and traffic safety".

4. Stavica JA (2015) "Transport systems of cities".

5. Borovsky BE (2015) "the Safety of road transport".

6. Gudkov VA, Mirotin LB (2007) Technology, organization and management of passenger road transportations. - Moscow: Transport, 2007. - 254 p.
7. Danilov EP (2005) Automotive business. Moscow: KnoRus, 2005. - 592 p.

8. Dmitriev SN (2000) The road patrol service. Moscow: Spark, 2000. -656 p.

9. Egiazarov VA (2006) Transport law: Textbook for universities. (4-e Izd., ster.). "Justitsinform", 2006.

10. Klinkovsky GI, Afanas'ev MB (2007) traffic management: Textbook for universities. -6 th ed. Rev. and extra - Moscow: Transport, 2007. 